\title{
ANÁLISE TEXTUAL DISCURSIVA: PROCESSO RECONSTRUTIVO DE MÚLTIPLAS FACES
}

\author{
Discursive textual analysis: a multiple \\ face recontructive process
}

\author{
Roque Moraes ${ }^{1}$ \\ Maria do Carmo Galiazzi²
}

\begin{abstract}
Resumo: 0 artigo, resultado de pesquisa qualitativa de dissertações e relatos de mestres que utilizaram a análise textual discursiva como ferramenta analítica, descreve a análise textual discursiva como procedimento de pesquisa que permite quatro reconstruções concomitantes: 1 . do entendimento de ciência e de seus caminhos de produção; 2. do objeto da pesquisa e de sua compreensão; 3. da competência de produção escrita; 4 . do sujeito pesquisador. Argumenta-se que a análise textual discursiva cria espaços de reconstrução, envolvendo-se nisto diversificados elementos, especialmente a compreensão da produção de significados sobre os fenômenos investigados e a transformação do pesquisador.
\end{abstract}

Palavras-chave: Análise textual discursiva. Paradigma emergente. Autoria.

\begin{abstract}
The paper describes the result of qualitative research of two graduate programs that used in their researches an analytical approach called "discursive textual analysis". This methodology produced four simultaneous results: 1 a reconstruction of the understanding of science and its ways of production; 2 the reconstruction of the research object and its comprehension; 3 the reconstruction of the competence in writing; 4 the reconstruction of the research itself. The authors argue that discursive textual analysis produces an environment in which different elements are reconstructed, especially the understanding of meaning production in science and a continuous transformation of the research itself.
\end{abstract}

Keywords: D iscursive textual analysis. Emergent paradigm. Authorship.

\footnotetext{
${ }^{1}$ D ocente, Pontifícia Universidade Católica do Rio G rande do Sul, Faculdade de Q uímica e Programa de PósGraduação em Ensino de Ciências. <searom@ pucrs.br>

${ }^{2}$ D ocente, Universidade Federal do Rio Grande, D epartamento de Química e Programa de Pós-G raduação em Educação Ambiental. <mcgaliazzi@yahoo.com.br>
} 
Moraes, R.; Galiazzi, M. C.

\section{Introdução}

A fase da análise de dados e informações constitui-se em momento de grande importância para o pesquisador especialmente numa pesquisa de natureza qualitativa. Constitui razão de ansiedade e insegurança para grande número de alunos de mestrado.

Este texto apresenta resultados de pesquisa realizada com mestres sobre vivências na construção de suas dissertações, utilizando a análise textual discursiva como ferramenta analítica (MORAES, 2003; MORAES e GALIAZZI, 2005). Foram examinadas doze dissertações concluídas com o uso dessa modalidade de análise (ARAÚJO, 2003; BAUMGARTEN, 2003; CARLOTTO, 2004; COSTA, 2005; FERREIRA, 2004; MAGALHÃES, 2002; OLIVEIRA, 2003; PED RINI, 2003; SCHAEFFER, 2003; SO UZA, 2004; ZAG O, 2003; ZIMMER, 2004), além de dezesseis depoimentos descrevendo os usos diversificados da metodologia pelos sujeitos da pesquisa. As dissertações foram analisadas a partir de cópias das bibliotecas das Instituições em que foram produzidas e os depoimentos foram obtidos em forma escrita por correspondência em correio eletrônico, a partir de instrumento encaminhado aos participantes.

A análise textual discursiva é uma abordagem de análise de dados que transita entre duas formas consagradas de análise na pesquisa qualitativa que são a análise de conteúdo e a análise de discurso. Existem inúmeras abordagens entre estes dois pólos, que se apóiam de um lado na interpretação do significado atribuído pelo autor e de outro nas condições de produção de um determinado texto. Ainda que o termo análise tex tual, segundo Titscher et al. (2002), possa relacionar-se a uma diversidade de abordagens de análise, incluindo-se nisto a análise de conteúdo e as análises de discurso, no presente texto o termo análise tex tual discursiva assume um sentido específico, conforme expresso em síntese a seguir.

A análise textual discursiva é descrita como um processo que se inicia com uma unitarização em que os textos são separados em unidades de significado. Estas unidades por si mesmas podem gerar outros conjuntos de unidades oriundas da interlocução empírica, da interlocução teórica e das interpretações feitas pelo pesquisador. Neste movimento de interpretação do significado atribuído pelo autor exercita-se a apropriação das palavras de outras vozes para compreender melhor o texto. D epois da realização desta unitarização, que precisa ser feita com intensidade e profundidade, passa-se a fazer a articulação de significados semelhantes em um processo denominado de categorização. Neste processo reúnem-se as unidades de significado semelhantes, podendo gerar vários níveis de categorias de análise. A análise textual discursiva tem no exercício da escrita seu fundamento enquanto ferramenta mediadora na produção de significados e por isso, em processos recursivos, a análise se desloca do empírico para a abstração teórica, que só pode ser alcançada se o pesquisador fizer um movimento intenso de interpretação e produção de argumentos. Este processo todo gera meta-textos analíticos que irão compor os textos interpretativos. Maiores detalhes sobre a análise tex tual discursiva podem ser encontrados no artigo uma tempestade de luz (MORAES, 2003).

Procura-se demonstrar no presente texto que 0 envolvimento na análise textual discursiva propicia duas reconstruções concomitantes: 1 . do entendimento de ciência e de seus caminhos de produção; 2 . do objeto da pesquisa e de sua compreensão. Argumenta-se no texto, sempre a partir das vivências de quem passou pelo processo, que a análise textual discursiva cria espaços de reconstrução, envolvendo-se nisto diversificados elementos, especialmente a compreensão dos modos de produção da ciência e reconstruções de significados dos fenômenos investigados. 


\section{N ovos caminhos de compreender a ciência e seus fazeres}

Neste item procura-se demonstrar que a visão de ciência dos pesquisadores em formação vai se transformando e o sinal desta transformação são as expressões de convivência com a insegurança, característica de uma nova forma de compreender a ciência. Como este é um processo novo para o pesquisador iniciante, é carregado de sentimentos de angústia, sinal, mais uma vez de possibilidade de aprendizagem.

Os relatos mostram que se envolver no tipo de análise proposto pela análise textual discursiva exige reconstrução dos entendimentos de ciência, superando paradigmas e solicitando construção de caminhos próprios de pesquisa. Isso implica em uma dialética entre insegurança e satisfação, entre prazer e angústia, exigindo aprender a lidar com a insegurança ao longo da pesquisa.

Os mestres investigados, ao avaliarem os caminhos percorridos, mostram que isso exigiu construção de sua própria metodologia, exercício de aprendizagem que se torna efetivo com o envolvimento intenso na prática da análise. Construir os próprios caminhos representa um conjunto de movimentos em que o ponto de chegada e seu direcionamento necessitam permanentemente serem revistos. Ao final é que o pesquisador consegue atingir maior segurança e clareza do caminho percorrido.

Para problemas de pesquisa originais, dos quais evidentemente nem bem se conhecem as perguntas feitas, não há possibilidade de antemão conhecer os modos de compreensão do fenômeno investigado a serem possibilitados pela pesquisa. As respostas são obtidas mais por uma construção da pergunta durante o processo de pesquisar. 0 processo da análise constitui "jornada complexa em que certezas se transformam em dúvidas, muitos caminhos se desviam e novos horizontes vão se configurando e tornando-se realidade" ${ }^{3}$. O u seja, o que era resposta, a certeza adquirida em um momento, passa a ser pergunta. Por isso é natural que numa pesquisa se invista muito tempo para avançar e que se acumulem muitas angústias à procura de um método adequado e seguro. No movimento gradativo e tateante, de uma sensação de insegurança inicial, o processo da análise possibilita avançar para um estágio de construção dos argumentos que fundamentarão a dissertação.

As vivências dos mestrandos mostram que a compreensão dessa metodologia é favorecida pela prática. "Quando se trata de escrever uma dissertação de mestrado, nenhuma experiência anterior parece ser suficiente". Concluído o processo, é fácil descrevê-lo, mas isso é "de pouca serventia para a orientação do que há a fazer" ao iniciar. A análise textual discursiva mais do que um conjunto de procedimentos definidos constitui metodologia aberta, caminho para um pensamento investigativo, processo de colocar-se no movimento das verdades, participando de sua reconstrução. Ė abordagem claramente incluída em metodologias que se situam em um paradigma de pesquisa emergente (SANTOS, 2002).

Caminho indefinido e em construção implica necessariamente inseguranças. "Na pesquisa, como em toda obra de arte, a segurança se produz na incerteza dos caminhos" (MAR-

\footnotetext{
${ }^{3}$ Citações que aparecem no texto entre aspas em letra cursiva normal correspondem a interlocuções empíricas com os sujeitos da pesquisa, obtidas a partir dos depoimentos escritos dos participantes.
} 
QUES, 1997, p. 114). 0 mestrando que trabalha com a análise textual discursiva não tem, ao início, uma visão clara e completa do processo todo, necessitando movimentar-se nele como quem navega construindo o mapa enquanto avança: "Recordo-me que passei uma semana sentada na frente do computador, escrevendo e deletando tudo. Acreditava que não era por ali o caminho". 0 procedimento da pesquisadora revela uma visão de ciência pautada na verdade. Para ela existia um jeito de fazer as coisas. Uma visão dicotômica entre o certo e 0 errado, focalizada mais no produto que ela queria alcançar, jogando o processo fora. 0 processo recursivo da pesquisa que produz por sucessivas aprendizagens e refazeres estava em construção.

Pergunta Maturana (1997, p. 4): “O que é uma resposta aceitável? Cada vez que se quer responder a uma pergunta, a dificuldade principal está em saber quando se tem a resposta. Como reconhecer uma resposta adequada se não se sabe de antemão qual é?" Assim, não apenas o caminho é incerto e inseguro, mas também a indefinição em relação ao ponto de chegada constitui desafio e fonte de angústias para os mestrandos. Como saber se foi atingida uma meta se é indefinido o ponto de chegada?

O s mestres ao avaliarem o processo após terem percorrido todo o caminho da análise e da escrita enfatizam que, mesmo entendendo que iniciar o processo é difícil, cada etapa tem suas dificuldades, e que é preciso ir avançando passo a passo. As coisas nem sempre correm de forma fluente. Entretanto, "mesmo sendo um processo trabalhoso, o fim justifica e compensa os meios". Alcançar um fim, no entanto, não significa saber qual seria o ponto de chegada. E o ponto de partida se torna claro na medida em que se chega no ponto de chegada.

Alguns mestrandos ao longo do processo parecem arrependidos de terem feito opção por essa metodologia, mas com 0 afastamento, afirmam querer continuar na mesma abordagem em outros estudos. Para a maioria foi experiência interessante e surpreendente: "tive a sensação de ter em minhas mãos uma vara de condão, que transformava os fragmentos coletados em densos sustentáculos das premissas teóricas anteriormente verificadas". Este depoimento leva a pensar na possibilidade da análise textual discursiva em construir teorias. 0 depoimento caminha em sentido oposto, em que as teorias existem antes da pesquisa. Considera-se, entretanto, mais interessante os processos de pesquisa em que as teorias são construídas em um intenso diálogo teórico-empírico.

A utilização da análise textual discursiva tem mostrado tratar-se de uma ferramenta aberta, exigindo dos usuários aprender a conviver com uma abordagem que exige constantemente a (re)construção de caminhos.

Ao mesmo tempo há a percepção de um instrumento com grande potencial para fazer emergir a criatividade. O s mestres indicam que trabalhar com a análise textual discursiva exige disciplina e rigor, acarretando de modo simultâneo o prazer propiciado por um trabalho criativo e original. A construção do novo é sempre insegura, exigindo ao máximo a criatividade, processo ao mesmo tempo rigoroso, prazeroso e gratificante. "D epois de iniciado, com disciplina, organização, dedicação e disponibilidade para leitura crítica, reflexão e reescritas sucessivas, a produção escrita do relatório de pesquisa torna-se uma atividade gratificante".

É de destacar a diversidade de envolvimentos exigidos para atingir-se uma produção que gratifique, mostrando que "todo o processo é de extremo trabalho, muita leitura e escrita". Isso coincide com o expresso por Marques (1997, p. 73): "disciplina e criatividade, antes de se oporem, se exigem em reciprocidade e são geradas a par". 0 criativo e original, mesmo que produzido em processos auto-organizados e emergentes, requer trabalho árduo e envolvimento intenso. 
$\mathrm{Na}$ análise textual discursiva as realidades investigadas não são dadas prontas para serem descritas e interpretadas. São incertas e instáveis mostrando que "idéias e teorias não refletem, mas traduzem a realidade" (MORAE S, 2004, p. 199) e por que não pensar que produzem a própria realidade, realidade de discurso sempre em movimento.

Esses espaços inseguros de criação constituem ao mesmo tempo possibilidade de 0 pesquisador movimentar-se com liberdade. Os mestrandos no uso desta metodologia, mesmo se percebendo inseridos na academia com suas regras e exigências consideram-se livres para fazerem suas próprias escolhas, processo que carrega certo grau de insegurança. Por isso, os movimentos de pesquisa com base na análise textual discursiva exigem uma intensa impregnação nos fenômenos investigados. Mais do que superar a incerteza e a insegurança é preciso aprender a com ela conviver, percebendo os progressos e êxitos e a partir disso adquirir confiança nos produtos atingidos.

A impregnação se concretiza a partir leituras e releituras, transcrições, unitarização e categorização e especialmente a partir da escrita. "O processo é de intensa impregnação. Se assim não fosse não seria possível tamanha produção". Esta manifestação indica que, uma escrita mais fluida e de qualidade, é produto de envolvimento e de impregnação intensos com os materiais da análise.

A impregnação é condição para um trabalho criativo e original. A partir do envolvimento aprofundado é que se criam condições de emergência auto-organizada das novas compreensões. Nisso desempenha papel importante a unitarização, correspondendo a momento de aproximação do caos, portanto, de possibilidades de emergência do novo pela desorganização de um texto que constrói uma outra ordem.

Ao valorizar esses aspectos, esta metodologia de análise se aproxima dos modos de funcionamento de sistemas complexos. Na análise, entretanto, "a complexidade não se reduz à incerteza. É a incerteza no seio de sistemas ricamente organizados" (MO RIN , 2003, p. 52). Ainda assim, atingir um conhecimento mais complexo e rico implica mover-se por espaços mais inseguros. Não é sentir-se inseguro por não ter aprendido. É ter aprendido a estar inseguro.

Isso é produzir mudanças no entendimento de ciência e os mestrandos durante as análises necessitam perceber seus progressos e êxitos. Isso, geralmente, implica sentir-se parte integrante do processo, dar-se conta de que os próprios conhecimentos e teorias estão sendo questionados e reconstruídos. Perceber a validade e qualidade do produzido é forte motivador para continuar num trabalho árduo e disciplinado.

Do exposto percebe-se que a análise textual discursiva é acompanhada de forma intensa por um conjunto de sentimentos. 0 pesquisador precisa compreender que eles são inerentes ao processo, parte da angústia da desorganização e do caos que precedem a criação de novas ordens e entendimentos. "A angústia é uma das maiores companheiras neste processo". Ter que definir um caminho em meio a dúvidas e indefinições causa medo e angústia, originando dúvidas sobre as condições para concluir a dissertação, quando se pensa que fazer ciência é seguir um único método que vai permitir fazer perguntas bem definidas para se alcançar respostas a estas perguntas feitas de antemão na pesquisa. "Penso que, por ser a primeira experiência com uma pesquisa cooperativa, em dado momento, fiquei muito aflita, sem saber o que fazer com tantas informações". Todo o processo da análise, mas especialmente a escrita, é acompanhado de medo, dúvida e incerteza.

Esses sentimentos eventualmente paralisam, mas, se podem dificultar os avanços, também podem ser desafiadores. É importante percorrer a jornada, ainda que difícil, com 
prazer, considerando aspectos positivos e negativos, vendo neles oportunidades de crescimento. Nesse turbilhão de emoções, a análise textual discursiva dá segurança, ajudando a lidar com as informações coletadas. Ou seja, a metodologia que aposta na sua construção ao longo do processo possibilita ao aluno aprender a conviver com a insegurança: "A emoção que se tem quando surge uma nova idéia, uma nova compreensão dos fenômenos é indescritível e emocionante". Assim os avanços percebidos propiciam prazer, ainda que em combinação com outros sentimentos. Uma mestranda denomina a análise textual discursiva de "efeito funil", tentando mostrar que exige muito trabalho e envolvimento para no final se chegar a um metatexto com qualidade. "A partir da análise textual discursiva, o trabalho de análise e organização do material de pesquisa já não pareceu uma missão impossível".

Ao percorrer os caminhos da análise emergem em pólos opostos prazer e dor, insegurança e convicção, solidão e solidariedade, todos propiciando espaços para a emergência do novo. Saber lidar com esses sentimentos é parte de um bom trabalho de análise. Sinalizar para esta aprendizagem é situar-se em um paradigma emergente de pesquisa.

Ao serem considerados esses aspectos mostra-se que 0 envolvimento com a análise textual discursiva implica ruptura com o paradigma dominante de ciência, fundamentado em suposta verdade, objetividade e neutralidade. Nesse tipo de análise exige-se do pesquisador mergulhar em seu objeto de pesquisa, assumindo-se sujeito e assumindo suas próprias interpretações. Nesse movimento hermenêutico são solicitadas constantes retomadas do concretizado, visando a permanente qualificação dos resultados.

A capacidade de observar e de refletir é conseqüência da operação do sujeito como sistema vivo, sistema auto-poiético, fundamentado na linguagem, possibilitando permanentes reconstruções de elementos anteriormente construídos. 0 contato com a realidade, feito pela linguagem, exige interpretação do sujeito, em que este precisa deixar sua marca. É impossível observar os fenômenos de fora. Concorda-se com Moraes (2004, p. 242) quando afirma que "sabemos por experiência própria, que em toda tradução existe alguma traição e que em toda interpretação existe reconstrução por parte daquele que interpreta". Isso se aplica muito apropriadamente à análise textual discursiva, pois "é impossível fazer uma pesquisa na qual se almeje a neutralidade do pesquisador e a objetividade da análise. Toda análise é subjetiva, fruto da relação íntima do pesquisador com seu objeto pesquisado".

Abandonar-se aos processos auto-organizados e emergentes da análise textual discursiva implica deixar que as idéias se insiram nas novas compreensões. Esse movimento, seguidamente, representa insegurança, pois o pesquisador se questiona até onde pode integrar suas convicções com as dos sujeitos pesquisados. Questiona seus limites de objetividade. Isso ocorre porque ao mesmo tempo em que se insere no paradigma emergente (SANTOS, 2002), a análise textual discursiva assume entendimentos da realidade como sistema complexo, abrindo-se com isso possibilidade de conhecimentos ao mesmo tempo mais ricos e seguros (MORIN , 2003). Há um elo muito forte entre desorganização e organização complexa.

A análise textual discursiva constitui processo recursivo continuado para uma maior qualificação do que foi produzido. "O processo da análise textual discursiva é um constante ir e vir, agrupar e desagrupar, construir e desconstruir". É um processo em que o pesquisador movimenta-se com as verdades que tenta expressar: "o processo da escrita final foi riquíssimo. Cada vez que entregava uma versão da dissertação e que recebia as contribuições de minha orientadora, tinha a sensação de que um novo trabalho estava se configurando, novos olhares, rumos e indagações". Ainda que sentindo os avanços, o pesquisador nunca tem certeza da 
qualidade, originalidade e pertinência de sua produção. Isso também será construído ao longo da pesquisa em uma rede de argumentos e vozes tecidas na interlocução empírica e teórica.

Assim, o pesquisador não parte com um caminho traçado e precisa ir redirecionando o processo enquanto avança por ele. Procura explorar as paisagens por onde passa, refazendo seus caminhos. Isso constitui uma reconstrução dos entendimentos de ciência e de pesquisar, reconstruções em que se evidencia um movimento em direção a novos paradigmas, com ênfase na autoria de um sujeito que assume sua própria voz ao mesmo tempo em que dá voz a outros sujeitos.

\section{N ovas compreensões do objeto de pesquisa}

A linguagem desempenha um papel central na análise textual discursiva. É por ela que o pesquisador pode inserir-se no movimento da compreensão, de construção e reconstrução das realidades. Pela linguagem constrói e amplia os campos de consciência pessoais, entrelaçando-os com os de outros sujeitos, sempre a partir dos contextos que investiga.

As experiências se concretizam pela linguagem. Os seres humanos produzem e são produzidos na linguagem. Na linguagem, o humano e seu mundo estão engajados em uma relação circular de co-produção (MATURANA, 1997, p. 13): "Existimos como seres humanos somente num mundo social definido por nosso ser na linguagem, sendo este 0 meio em que nos realizamos como seres vivos". D esse modo a significação de mundo nunca é completa. Nunca é dada, jamais é fechada. Solicita sempre que o sujeito participe de sua reconstrução em um processo lingüístico. 0 pesquisador ao envolver-se em uma análise textual discursiva assume de modo mais consciente esta reconstrução constante de seus mundos, sempre por intermédio da linguagem.

A consciência se constitui na linguagem, por meio da qual o campo de consciência se amplia constantemente. "A verdadeira substância da história é aquela das vidas, de todas as vidas: a soma não-totalizável das experiências e de suas relações. A história é a aventura da consciência. Uma vez mais reunida, cada vez mais consciência de si mesma" (Lévy, 2001, p. 41).

Concretizar uma análise textual é mergulhar no rio da linguagem, movimentar-se nele, assumir-se parte do meio. Por isso uma análise efetiva é contextualizada, o sujeito é parte do processo, sem possibilidade de objetividade e neutralidade do tipo positivista. "A consciência universal, feita de campos de consciência pessoais entrelaçados é atravessada por sensações, percepções, emoções e pensamentos impessoais que vagam sobre o grande rio que carrega todos nós" (LÉVY, 2001, p. 41).

O mergulho no rio da linguagem dentro do processo da análise textual discursiva, é inicialmente um movimento desconstrutivo, de identificação e expressão de unidades elementares obtidas a partir do material do corpus da pesquisa. Esse início denomina-se de unitarização, a fragmentação, codificação e atribuição de títulos a unidades elementares de sentido construídas a partir de uma leitura e impregnação intensa com o material da análise.

Unitarizar é interpretar e isolar idéias elementares de sentido sobre os temas investigados. Constitui leitura cuidadosa de vozes de outros sujeitos, processo no qual o pesquisador não pode deixar de assumir suas interpretações. Ao expressar múltiplas vozes, o processo consiste em um diálogo com interlocutores em que participam diversificados pontos de vista, sempre expressos na voz do pesquisador. Na unitarização os textos submetidos à análise são 
recortados, pulverizados, desconstruídos, sempre a partir das capacidades interpretativas do pesquisador. Nisso fica presente sua autoria, ao mesmo tempo que seu limite. O utro pesquisador faria outras seleções, estabeleceria outros argumentos, faria outras tecituras: "Esse momento da análise foi muito interessante, pois permitiu examinar as informações que se apresentavam de forma complexa e podiam comunicar várias idéias, sempre a partir do meu olhar e da minha subjetividade enquanto pesquisadora. ... A cada leitura novas compreensões". Ao ler, interpretar as vozes dos sujeitos da pesquisa, abrir-se à significação do outro, o pesquisador incorpora significados nos seus próprios entendimentos, constituindo sua aprendizagem no processo. Unitarizar é dar início ao processo reconstrutivo das compreensões do pesquisador, sempre a partir do mergulho em significados coletivos expressos pelos sujeitos da pesquisa.

0 processo da unitarização é inseguro, especialmente em seu início. Apenas o envolvimento possibilita conviver com esta insegurança. Implica em mover o sistema de idéias analisado para o caos, produzindo-se um conjunto desordenado e caótico de unidades elementares de significado sobre os temas investigados. 0 conjunto das unidades produzidas corresponde a um espaço criativo, de auto-organização, capaz de dar origem a novas combinações, criando as condições para a emergência do novo, sempre a partir do intercâmbio de sentidos.

Todo o processo da análise textual discursiva, e de modo especial a unitarização, constitui exercício de produção de novos sentidos, processo no qual, pela interação com outras vozes o pesquisador atualiza sentidos expressos. A desconstrução total nunca é atingida, exigindo constantes decisões sobre 0 encaminhamento do processo.

A unitarização é processo de colocar-se no movimento dos pensamentos da consciência coletiva, de reconstrução de significados compartilhados socialmente a partir da perspectiva pessoal do pesquisador. "Tanto o pensamento pessoal como o pensamento coletivo são circulações da atenção em um imenso espaço virtual de significações, uma fluida rede de representações, de imagens e de tonalidades emocionais capaz de reorganizar instantaneamente suas hierarquias e seus sistemas de distâncias" (LÉVY, 2001, p. 120).

Envolver-se no movimento desconstrutivo da unitarização corresponde a assumir-se leitor e intérprete nessas redes semânticas mais ou menos sedimentadas constitutivas das verdades sociais. Corresponde a participar dos processos reconstrutivos das compreensões anteriormente elaboradas, colocando nas novas formulações um ponto de vista próprio do pesquisador. Nesse sentido é preciso concordar com Lévy (2001, p. 120) quando afirma que sua hipótese "é que, na ordem psíquica, a consciência constitui a realidade de base, a energia última. Seu poder criador se traduz em idéias e em paisagens de espaço-tempo semântico".

Entretanto, como exercício de pesquisa científica, este processo está preocupado com o rigor. Unitarizar constitui processo rigoroso de construção de sentidos e compreensões, dependendo esses sentidos tanto de quem escreve quanto de quem lê um texto. Esse rigor não está na cópia fiel de sentidos dados pelos autores dos textos, mas num envolvimento intenso e construtivo do pesquisador. Não é a cópia que caracteriza o científico, mas a qualidade do que o pesquisador consegue produzir a partir das idéias de seus sujeitos de pesquisa: "o valor de nossas pesquisas depende do valor de nossas leituras". Uma leitura válida é a que atualiza significados, não apenas expressando o que foi inicialmente pretendido. "Ler é descortinar muitas leituras possíveis, é dilatar os horizontes das próprias percepções, horizontes dos muitos mundos abertos à inventividade criativa" (MARQUE S, 1997, p. 10). Um texto é atualizado em cada leitura. "Ao interpretar, ao dar sentido ao texto aqui e agora, o leitor leva adiante essa cascata de atualizações" (LÉVY, 2003, p. 35). 
Assim, é ilusão pensar que é obrigação do pesquisador captar o significado que os sujeitos da pesquisa pretenderam atribuir a suas afirmativas. Na leitura sempre ocorre transformação e atualização. Processo necessariamente inseguro e impreciso, implicando a inserção e mergulho do pesquisador para participar das reconstruções de modo rigoroso e original. 0 processo não pára aí. A partir da unitarização criam-se as condições para a categorização, com emergência de novos entendimentos e sentidos. As categorias vão emergindo, inicialmente imprecisas e inseguras, mas gradativamente sendo explicitadas com rigor e clareza.

Uma vez concretizada a impregnação nos materiais da análise, com intensa desorganização e desconstrução, as categorias emergem resultantes deste movimento de compreensão do que está sendo significado pelo pesquisador. "Tal fato não significa, contudo, que este processo seja automático e ágil. Fui e voltei diversas vezes, reposicionando os fragmentos, sempre na tentativa de evitar o equívoco na adequação dos mesmos às categorias". É processo recursivo e recorrente exigindo intensa participação: "a possibilidade de compactar idéias fragmentadas, oportunizando às mesmas o surgimento de um novo sentido, um novo significado".

"D ando passos adiante no processo da análise textual discursiva, identifico claramente 0 momento que consegui enxergar as categorias que emergiam". Este momento corresponde ao nascimento de outro espaço, "o espaço do prazer, no qual a escrita flui com rapidez". Entretanto, as categorias não nascem prontas, exigindo um retorno cíclico aos mesmos elementos para sua gradativa qualificação. 0 pesquisador precisa avaliar constantemente suas categorias em termos de sua validade e pertinência.

Cada categoria representa um conceito dentro de uma rede de conceitos que pretende expressar novas compreensões. As categorias representam os nós de uma rede. 0 pesquisador ao tecer sua rede precisa preocupar-se especialmente com os nós, ou seja, os núcleos ou centros das categorias. "As fronteiras são sempre vagas. Os conceitos não se definem nunca por suas fronteiras, mas a partir de seu núcleo" (MO RIN, 2003, p. 106). Por isso o processo de categorização precisa investir na definição e explicitação do núcleo das categorias emergentes, deixando que se estabeleçam entrelaçamentos na superposição das fronteiras, garantindo-se desta forma a constituição de um todo integrado. A superação da fragmentação na análise textual discursiva implica não pretender estabelecer limites precisos entre as categorias.

A combinação da unitarização e categorização corresponde a movimentos no espaço entre ordem e caos, em um processo de desconstrução que implica construção. A unitarização representa um movimento para o caos, de desorganização de verdades estabelecidas. A categorização é movimento construtivo de uma ordem diferente da original.

Realizar uma análise textual discursiva é saber movimentar-se em espaços entre ordem e caos. Seguidamente os pesquisadores iniciantes têm dificuldades com isso, resistindo ao momento desorganizativo, de desconstrução de ordens existentes por desconhecerem sua importância. "Hoje vejo o quanto estava enganada e principalmente percebo que o processo de construção e desconstrução é fundamental em um processo de interpretação". Conforme Morin (2003, p. 46), "a entropia, num sentido, contribui para a organização que tende a arruinar e a ordem auto-organizada só pode complexificar-se a partir da desordem". A emergência de novas formas de organização só pode se realizar a partir da destruição de ordens existentes. Prender-se ao ordenado e ao certo implica estacionar. Pode parecer seguro, mas não possibilita avançar. Entretanto, mover-se para o caos exige coragem, implica insegurança: "muitas vezes sentia-me inundada pelo material. Parecia não haver indicativo de que eu chegaria a algum lugar, uma desordem total". Mas, ao mesmo tempo, a (re)leitura dos materiais, impregnando- 
se dos fenômenos, possibilita emergir relações entre as partes e o todo, "a partir da desordem eu podia ver uma nova ordem", os flashes de luz que sugerem uma auto-organização.

É importante saber conviver com este momento de desorganização para possibilitar a emergência do novo. É no espaço entre caos e ordem, entre desorganização e categorização que surgem novas e criativas interpretações e compreensões. Uma escrita produtiva implica abandonar-se no espaço desorganizado da inconsciência. 0 processo em seu todo corresponde a um conjunto de movimentos auto-organizados.

Da mesma forma como alguns autores apontam para a produção escrita (TO LCHINSKY e SIMÓ, 2001), a análise textual discursiva tem uma primeira fase que pode ser denominada de "tempestade de idéias" na qual o analista mergulha nos temas que pretende explorar. Esta fase corresponde a um momento desconstrutivo, seja das idéias do pesquisador, seja das idéias de outros sujeitos. É dela que podem emergir novas compreensões, reconstruções de conhecimentos existentes. Esse processo não pode ser planejado linearmente. Novos entendimentos emergem por intuição.

O funcionamento da auto-organização, espaço entre a desorganização e a emergência do novo, não pode ser previsto, nem pode ser forçado. 0 pesquisador precisa ter paciência, deixar que o processo se auto-organize, implicando um afastamento "para deixar os dados descansarem um pouco". Muitas vezes, de forma repentina e inesperada, em momentos em que o pesquisador está desligado de sua produção, é que ocorrem os insights com novos entendimentos, embora isto só aconteça com muita impregnação, escrita e leitura durante a análise.

É importante acreditar que o processo funciona e saber aguardar pelas emergências. Entretanto, também é preciso atenção para captar e registrar o novo emergente quando aparece, pois é fugidio e passageiro, ainda que eventualmente intenso:: "acordei e tratei de jogar essas idéias no computador. Q uanto mais escrevia, mais coisas vinham a minha mente. Tudo que estava solto foi se juntando e tomando forma".

O movimento produtivo e criativo, portanto, corresponde a um processo auto-organizado composto de dois movimentos principais. 0 primeiro deles é de desconstrução, de desmontagem dos sentidos e conhecimentos existentes, de aproximação ao caos. 0 segundo é de reconstrução, de organização das unidades de sentido produzidas pela desconstrução, com emergência de categorias e textos expressando os novos entendimentos construídos no processo. Estes dois movimentos estão sempre acontecendo, embora possa se dedicar mais tempo a um e a outro em determinado momento da análise. A desconstrução é sempre uma reconstrução. Essas produções são sempre inacabadas, incompletas, solicitando constantes reescritas e aperfeiçoamentos.

\section{Considerações finais}

Procura-se demonstrar algumas das possibilidades da análise textual discursiva no encaminhamento da análise de informações de pesquisas qualitativas. D efende-se que esta é uma metodologia exigente, solicitando intensa impregnação do pesquisador. Este, ao longo do processo, é desafiado a reconstruir seus entendimentos de ciência e de pesquisa, no mesmo movimento em que reconstrói e torna mais complexas suas compreensões dos fenômenos que investiga. Como processo auto-organizado a análise textual discursiva cria espaços para a emergência do novo, uma tempestade de luzes surgindo do caos criado dentro do processo. 


\section{Referências}

ARAUJO, M. S. Construindo conceitos no ensino médio para sentir, pensar e atuar no ambiente. Rio Grande. 2003. Dissertação (Mestrado em Educação Ambiental) FURG.

BAUMgaRTEN, C. Ação Pedagógica como facilitadora do avanço de alunos de Turma de Progressão. Porto Alegre. 2003. Dissertação (Mestrado em Educação)Faculdade de Educação, PUCRS.

BERNARD O, G. Educação pelo argumento. Rio de Janeiro: Rocco, 2000.

CARLOTTO, F. R. H ipertextualidade como possibilidade metodológica complexa para uma educação transdisciplinar: uma pedagogia das relações. Porto Alegre. 2004. D issertação (Mestrado em Educação) - Faculdade de Educação, PUCRS.

CO STA, M. M. G. As teias do desmame no processo de amamentação de mães adolescentes. Rio Grande. 2005. Dissertação (Mestrado em Educação Ambiental) - FURG.

FERNÁNDEZ, A. 0 saber em jogo. Porto Alegre: Artmed, 2001.

FERREIRA, L. C. 0 diálogo na interação em educação à distância. Porto Alegre. 2004. D issertação (Mestrado em Educação) - Faculdade de Educação, PUCRS.

LÉVY, P. 0 que é virtual? São Paulo: Editora 34, 2003.

A conexão planetária: o mercado, o ciberespaço, a consciência. São Paulo: Editora 34, 2001.

MAGALHÃES, V. B. D. S. Professores pontocom: o que buscam e o que encontram na Web. Porto Alegre. 2002. Dissertação (Mestrado em Educação) - Faculdade de Educação, PUCRS.

MARQUES, M. O. Escrever é preciso: o princípio da pesquisa. Ijuí: Editora Unijuí, 1997.

MATURANA, H. R. La realidad: objetiva o construida? Rubi (Barcelona): Anthropos, 1997.

MORAES, M. C. Pensamento eco-sistêmico: educação, aprendizagem e cidadania no século XXI. Petrópolis: Vozes, 2004.

MORAES, R. Uma tempestade de luz: a compreensão possibilitada pela análise textual discursiva. Ciência \& Educação: Bauru, SP, v. 9, n. 2, p. 191-210, 2003. 
Moraes, R.; Galiazzi, M. C.

MORIN, E. Introdução ao pensamento complexo. Lisboa: Instituto Piaget, 2003. RAMOS, M. G.; M., R.; GALIAZZI, M. C. Arquitetos de transformação de discursos sociais: sujeitos que emergem da produção escrita reconstrutiva. In: ISCAR, 1., Sevilha, 2005. Anais...

OLIVEIRA, M. C. K. Educar para conviver: por uma pedagogia da solidariedade. Porto Alegre, 2003.

PED RINI, M. E stágio docente: uma experiência compartilhada. Porto Alegre. 2003. Dissertação (Mestrado em Educação) -Faculdade de Educação, PUCRS.

SÁNCHEZ, J-N. G.; M., J. M. Instrucción estratégica en la composición escrita. Barcelona: Ariel Educación, 2002.

SANTOS, B. S. Um discurso sobre as ciências. Porto: Afrontamento, 2002.

SCHAEFFER, A. Inteligência espiritual ampliada e prática docente bem sucedida: uma tessitura que desvela outros rumos para a educação. Porto Alegre. 2003. Dissertação (Mestrado em Educação) - Faculdade de Educação, PUCRS.

SO UZA, M L. Educação Ambiental na Escola: Interações nas Vivências de um trabalho Coletivo. Rio Grande. 2004. Dissertação (Mestrado em Educação Ambiental) - FURG.

TITSCHER, S.; MAYER, M.; WODAK, R.; VETTER, E. Methods of text and discourse analysis. London: Sage, 2002.

TO LCHINSKY, L.; SIMÓ , R. Escribir y leer a través del curnículum. Barcelona: ICI HORSO RI, 2001.

ZAG O, C. U. Alternativas para trabalhar as dificuldades de aprendizagem baseadas no lúdico. Porto Alegre. 2003. Dissertação (Mestrado em Educação) - Faculdade de Educação, PUCRS.

ZIMMER, R. O. D. Registro reflexivo do agir e do pensar de um grupo encantadamente comprometido com a proposta curricular transformadora. Porto Alegre. 2004. D issertação (Mestrado em Educação) - Faculdade de Educação, PUCRS.

Artigo recebido em fevereiro de 2006 e aceito em abril de 2006. 